NASA/TM-2005-213832

\title{
Approaches to Validation of Models for Low Gravity Fluid Behavior
}

David J. Chato

Glenn Research Center, Cleveland, Ohio

Jeffery Marchetta and John I. Hochstein

University of Memphis, Memphis, Tennessee

Mohammad Kassemi

National Center for Space Exploration Research, Cleveland, Ohio 
Since its founding, NASA has been dedicated to the advancement of aeronautics and space science. The NASA Scientific and Technical Information (STI) Program Office plays a key part in helping NASA maintain this important role.

The NASA STI Program Office is operated by Langley Research Center, the Lead Center for NASA's scientific and technical information. The NASA STI Program Office provides access to the NASA STI Database, the largest collection of aeronautical and space science STI in the world. The Program Office is also NASA's institutional mechanism for disseminating the results of its research and development activities. These results are published by NASA in the NASA STI Report Series, which includes the following report types:

- $\quad$ TECHNICAL PUBLICATION. Reports of completed research or a major significant phase of research that present the results of NASA programs and include extensive data or theoretical analysis. Includes compilations of significant scientific and technical data and information deemed to be of continuing reference value. NASA's counterpart of peerreviewed formal professional papers but has less stringent limitations on manuscript length and extent of graphic presentations.

- TECHNICAL MEMORANDUM. Scientific and technical findings that are preliminary or of specialized interest, e.g., quick release reports, working papers, and bibliographies that contain minimal annotation. Does not contain extensive analysis.

- CONTRACTOR REPORT. Scientific and technical findings by NASA-sponsored contractors and grantees.
- CONFERENCE PUBLICATION. Collected papers from scientific and technical conferences, symposia, seminars, or other meetings sponsored or cosponsored by NASA.

- SPECIAL PUBLICATION. Scientific, technical, or historical information from NASA programs, projects, and missions, often concerned with subjects having substantial public interest.

- TECHNICAL TRANSLATION. Englishlanguage translations of foreign scientific and technical material pertinent to NASA's mission.

Specialized services that complement the STI Program Office's diverse offerings include creating custom thesauri, building customized databases, organizing and publishing research results ... even providing videos.

For more information about the NASA STI Program Office, see the following:

- Access the NASA STI Program Home Page at http://www.sti.nasa.gov

- E-mail your question via the Internet to help@sti.nasa.gov

- Fax your question to the NASA Access Help Desk at 301-621-0134

- Telephone the NASA Access Help Desk at 301-621-0390

- Write to:

NASA Access Help Desk

NASA Center for AeroSpace Information 7121 Standard Drive

Hanover, MD 21076 
NASA/TM-2005-213832

AIAA-2004-1150

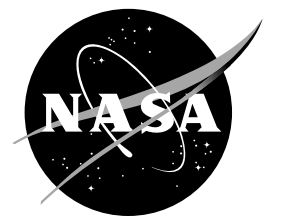

\section{Approaches to Validation of Models for Low Gravity Fluid Behavior}

David J. Chato

Glenn Research Center, Cleveland, Ohio

Jeffery Marchetta and John I. Hochstein

University of Memphis, Memphis, Tennessee

Mohammad Kassemi

National Center for Space Exploration Research, Cleveland, Ohio

Prepared for the

42nd Aerospace Sciences Meeting and Exhibit

sponsored by the American Institute of Aeronautics and Astronautics

Reno, Nevada, January 5-8, 2004

National Aeronautics and

Space Administration

Glenn Research Center 
Available from

NASA Center for Aerospace Information 7121 Standard Drive

Hanover, MD 21076
National Technical Information Service 5285 Port Royal Road Springfield, VA 22100

Available electronically at http://gltrs.grc.nasa.gov 


\title{
Approaches to Validation of Models for Low Gravity Fluid Behavior
}

\author{
David J. Chato \\ National Aeronautics and Space Administration \\ Glenn Research Center \\ Cleveland, Ohio 44135 \\ Jeffery Marchetta and John I. Hochstein \\ The University of Memphis \\ Mechanical Engineering Department \\ Memphis, Tennessee 38152 \\ Mohammad Kassemi \\ National Center for Space Exploration Research \\ Cleveland, Ohio 44135
}

\begin{abstract}
This paper details the author experiences with the validation of computer models to predict low gravity fluid behavior. It reviews the literature of low gravity fluid behavior as a starting point for developing a baseline set of test cases. It examines authors' attempts to validate their models against these cases and the issues they encountered. The main issues seem to be that: Most of the data is described by empirical correlation rather than fundamental relation; Detailed measurements of the flow field have not been made; Free surface shapes are observed but through thick plastic cylinders, and therefore subject to a great deal of optical distortion; and Heat transfer process time constants are on the order of minutes to days but the zerogravity time available has been only seconds.
\end{abstract}

\section{Introduction}

Each of the authors of this paper has extensive experience modeling low-gravity flow with Computational Fluid Dynamics. Dr. Chato, (refs. 1 and 2) working mostly with a NASA developed phase field model of the free surface, (ref. 3) Drs. Hochstein and Marchetta with the Volume of Fluid (refs. 4 and 5)-Continuum Surface Force (ref. 6) code ECLIPSE, and Dr. Kassemi with the finite element code FIDAP (ref. 7). All codes have their strengths and weaknesses and each author has had some success with his approach. One of the major hurdles each has encountered is a lack of validation data with which to compare his results with. Although much drop tower work was conducted in the sixties and seventies, it is typically published in a form which does not contain enough information to analyze the flow field. Most data is published in a few static photographs and the bulk of the data is compressed into an empirical correlation. Most of the raw drop tower film has been lost to the ravages of time. Even when film is available, flow visualization is not, so the velocity field is inferred rather than measured. At best, one can look at the injection of dye and infer the fluid motion roughly from that. The purpose of this paper is to examine what research is available and open a dialog within the research community as to where to go from here.

\section{The Role of Verification and Validation in CFD}

The computational community has spent a great deal of time trying to establish methods for insuring the correctness of their models. Verification and Validation (V\&V) of simulations are becoming the primary means for increasing and quantifying confidence in computational results in many disciplines (ref. 8). Simply, verification is the assessment of the accuracy of the solution of a computer model by comparison with known solutions. Validation is the assessment of the accuracy of a computer model with experimental or 'real' world data. In verification, the ability of the simulation to accurately represent the 'real' world is not assessed. While the terminology has been used informally for years, quantitative $\mathrm{V} \& \mathrm{~V}$ is beginning to be gain recognition as verification and validation science. In the United States, the Defense Modeling and Simulation Office (DMSO) of the Department of Defense has been a leader in the development of fundamental concepts and terminology for $\mathrm{V} \& \mathrm{~V}$ (refs. 9 and 10). In addition, the Accelerated Strategic Computing Initiative (ASCI) program of the Department of Energy (DOE) has also taken a strong interest in $\mathrm{V} \& \mathrm{~V}$ by recognizing the need for methods, procedures, and processes for properly performing and quantifying $\mathrm{V} \& \mathrm{~V}$. The field of computational fluid 
dynamics (CFD) has been a pivotal leader in identifying the need for verification and quantifying confidence in simulation.

Recognizing the value in both simulation and experiment, agencies have gradually shifted research funding more equitably in recent years. Despite this awareness, significant challenges exist in creating a cooperative working environment between computationalists and experimentalists. The major obstacle is that experiments designed for validation are different from traditional experiments. For example, a comparison of simulation results and experiment results requires a detailed characterization of experiment conditions and uncertainty estimation of the measurements. Traditionally, computer models were verified, numerical error estimates were established, and a minimal validation effort was performed. Modern validation activities adopt a tiered approach where uncertainty present in experimental parameters, initial conditions, and boundary conditions is incorporated into deterministic simulations. In essence, this merger emulates a nondeterministic simulation by performing multiple deterministic simulations that include the experimental uncertainty.

A fundamental strategy has been adopted for verification and validation efforts. For verification, the assessment begins by the identification and quantification of errors in the discretized model. This error is a product of using numerical approximations to discretize the exact formulation. The accuracy of the computational solution is measured with respect to analytic solutions, or highly accurate numerical solutions. The second verification task is to identify errors in the computer implementation of the model or the program. Rigorous debugging activity and software quality engineering are essential trademarks of this portion of the verification effort. These two principle tasks can be distinguished as the difference between code verification and solution verification. Software developers are aware of the need for, and have been conducting extensive verification testing, as a standard practice for some time. Roache (ref. 11) provides a detailed methodology and procedures for performing verification assessment. It is only necessary to refer to this and a few related sources to highlight the need to appropriately identify tests that are relevant to microgravity simulation verification. Because verification assessment is so well defined, a summary is sufficient in emphasizing its partnership with validation. Although verification can be quite challenging, the issues faced by the low gravity fluid modeler are not significantly different from any other CFD. Verification will not be addressed further in this paper.

Validation assesses how accurately the computational model results compare with experimental data, with quantified error, and with uncertainty. It is impossible to prove mathematically that a model is validated. Codes cannot be validated, only the individual outcomes of each simulation are validated. The level of confidence in computational predictions of complex physical processes can only be inferred from the level of the validation. A validation effort should be focused on evaluating the fidelity of the mathematical model and not on the solution accuracy of the discretized model. From this description, it is apparent that comprehensive verification should be performed prior to validation.

In 1992, the AIAA Computational Fluid Dynamics Committee on Standards began standardizing the terminology, methodology, and philosophy of $\mathrm{V} \& \mathrm{~V}$ activities in CFD. The AIAA guide (ref. 12) recommends a hierarchy for validation activities aimed at identifying appropriate experiments, coupled physical processes, and levels of complexity. A multi-tier approach begins with an experiment aimed at validating a single physical model and ends with experiments and simulations of complex engineering systems. The number of tiers depends on the ability to separate coupled physical processes and the ability to select or conduct experiments that are practical and that produce quality data for validation. In addition, physical complexity such as geometry, temporal character, and dimensionality may require additional layers of validation. Experiments should be reasonable and yield measurements of various system-response events for the purpose of testing the simulation. The ability to conduct validation experiments can be challenging on many levels. At the lowest level, it may be difficult to isolate individual physical processes in an experiment and then devise instrumentation to measure the events of interest. At the top-tier, the acquisition of validation measurements from complex systems is complicated by the operational infrastructure or hardware. The benchmark database should include measurements from a set of experiments designed to span several layers of complexity. The experiment must be well defined and performed to so that experimental uncertainty can be statistically estimated with precision.

Oberkampf and Trucano (ref. 8) suggest several guidelines for designing and conducting validation experiments. Among these guidelines, they stress that validation experiments should be cooperatively designed by experimentalists, model developers, code developers, and code users. While joint activities are essential, consideration must be given to an experiment environment where results are obtained independently to avoid bias. The experiment should reflect the physics of interest, and the boundary and initial conditions to be used by the code, yet constructed to analyze and precisely determine the experimental errors. Most importantly, the experiment should embody the symbiosis between computational and experimental methods. A synergetic relationship between all components of the research community should propagate continual improvement, knowledge, and accuracy in both experimental and computational approaches.

Although several benchmark databases for validation are under development, low gravity fluid behavior is not a phenomena included in any database of which the authors 
are aware. It falls to the low gravity fluid behavior community to establish their own benchmark cases. The next section will present several classic problems of low gravity fluid behavior as possible benchmark cases. Note: the achievement of true benchmarks in other fields of CFD has required dedicated experiments, specifically designed with concept of code validation in mind, and there is every reason to expect this will also be the case for low gravity fluid behavior.

\section{Low Gravity Problems}

\section{Static Meniscus Shape}

Analysis. - The meniscus problem has been investigated by many well known names in numerical modeling including Laplace, Rayleigh, Runge, Bashford, and Adams (ref. 13). At the beginning of the space age it was the subject of several investigations. Reynolds, Saad, and Satterlee (ref. 14) reduced the fundamental forces in an axisysmmetric free surface to a pair of differential equations and then solved them numerically over a parametric range of Bond number and wall contact angle. Concus (ref. 13) reduced the solution for a right cylinder to a single differential equation. He then solved the asymptotic cases of very large and very small Bond number analytically and the in between cases numerically. Hastings (ref. 15) is notable for a computer algorithm to solve for static free surfaces in ellipsoidal tanks.

Drop tower tests.-Drop tower results confirm the predictions of analysis for many different shapes including a single right cylinder, (ref. 15) concentric cylinders, (refs. 16 and 17) spheres and ellipsoids, (ref. 18) and even cones (ref. 19). The cylinder in a cylinder led to some early fluid positioning concepts tested both with water on a Mercury flight (ref. 20) and with liquid hydrogen on a sounding rocket (ref. 21). Salzman's (ref. 18) work on spheres and ellipsoids is noteworthy for its discussion on the difficulties of trying to determine the free surface location from film of curved plastic tanks. The main issues are refraction of the interface image by the plastic and liquid; and the fact that the image of the interface usually appears as a dark band rather than a sharp line.

Model validation. - To test the performance of the phase field free surface model (ref. 2) the free surface was allowed to move from a flat initial starting condition to the equilibrium free surface shape in zero gravity. The equilibrium shape in zero gravity, taken from the small bond number asymptote of Concus, (ref. 13) is a segment of a sphere whose radius is calculated from the following relationship for different contact angles

$$
r_{\text {equiv }}=\frac{r_{\text {tank }}}{\cos \left(\theta_{\text {contact }}\right)}
$$

Figure 1 shows the evolution of equilibrium free surfaces from a flat interface. Agreement for the $60^{\circ}$ contact angle is very good. Agreement for the $0^{\circ}$ contact angle is also good except in the region near the wall. Grid resolution has truncated the tail of the free surface right at the wall. Agreement for the $30^{\circ}$ contact angle is fair. Examination of the time sequence revealed a strong transient which had not quite damped out by the end of the run: as a consequence the profile is a little flatter than it should be.

Meniscus shape in complex geometries.-An interesting extension of free surface shape analysis is the Surface Evolver code of Brakke (ref. 25) which uses energy minimization calculations to predict free surface shape in quite complex geometries. Tegart (ref. 26) showed the application of the model to actual tank shapes. Dominick and Tegart (ref. 27) used the code to compare predicted shapes in a complex vane liquid acquisition device with visual observation from the FARE II flight experiment. Collicott and Weislogel (ref. 28) working with Evolver by probing the eigenvalue of the free surface solution were able to understand the resistance to wetting of vaned devices. They used the theoretical predictions of Concus and Finn (ref. 29) to validate their modeling effort. In further work Collicott and Weislogel (refs. 30 and 31) extended their work to model the behavior of the Vented Tank Resupply Experiment (VTRE) (ref. 32) vane device flown as a Hitchhiker payload in the shuttle cargo bay, even to the extent of modeling the rewetting of the VTRE after an intentional spillage of the vane device by high maneuvers. A summary of their validation work with Surface Evolver was presented in 2003 (ref. 33).

Issues.-Static Meniscus shape lends itself to analysis very well. Experimental data is extensive but limited by issues of optical quality. Validation against the analysis has proven successful even in cases involving complex geometries.

\section{Time to Reach Equilibrium Static Shape}

Analysis and drop tower test.-The time history of the evolution of the free surface for a $0^{\circ}$ contact angle can be compared to the drop tower tests of Siegert (ref. 22). Siegert conducted a series of tests to determine the minimum time for fluid packages released in the drop tower to reach an equilibrium shape. Most of his results are recorded as the time the tip of the liquid interface first crosses the equilibrium position. The overall oscillation about the equilibrium was observed by Siegert (ref. 22) as well as other investigators such as Fung (ref. 23) and Hollister (ref. 24). However no quantitative data to determine the time accuracy of oscillations was presented.

Model validation.-Siegert's $4 \mathrm{~cm}$ tank was modeled with the phase field code (ref. 2). A time history of the free surface position at the centerline is plotted in figure 2 . The time of first crossing is in excellent agreement with Siegert 
Time oscillations of the free surface are also observed although their accuracy is unknown.

Issues.-Time to reach equilibrium static shape has been estimated empirically, but a careful experiment to investigate the transients of the process would be useful.

\section{Reorientation}

Analysis and drop tower testing.-Because of its involvement in the Centaur program and its interest in low-gravity fluid behavior, the NASA has conducted extensive research on the settling thrust maneuver. Lacovic et al. (ref. 34) explain the Centaur system as well as the difficulties encountered during its development. The Centaur uses $27 \mathrm{~N}$ of thrust to settle (at settling Bond number of 360). In parallel with the Centaur development the settling maneuver was investigated in the drop towers. Masica and Petrash (ref. 35) explored the motion of vapor in inverted partially liquid filled long cylinders and were able to develop a correlation using the Bond number. This correlation agreed with both $1 \mathrm{~g}$ and drop tower tests and reduced to the theoretical prediction for the rise rate of large bubbles in normal gravity once the bond number exceeded 12. Salzman and Masica (ref. 36) investigated the motion of liquid in propellant tank models. Results for bubble rise velocity agree with Masica and Petrash, (ref. 35) but the leading edge motion had to be corrected for the effect of the spherical tank bottom. They also observed that the liquid rebounded in a geyser along the tank center when Weber number based on this velocity and tank radius exceeded 4 . Salzman, Masica, and Lacovic (ref. 37) conducted research in a scale model Centaur tank and suggested that far less thrust than is currently used would be capable of equivalent settling times. This is due to the following phenomena. Much of the energy used to start the fluid motion is stored as momentum in the bulk liquid. When the liquid reaches the bottom of the tank, this momentum causes the moving liquid to rebound as a geyser along the tank centerline. High thrust levels can even cause the falling liquid to entrain large quantities of gas. Sumner (ref. 38) revisited the tests of the Centaur development era to minimize the total impulse used for settling maneuvers. His work suggested that the optimum settling thrusts generate Bond numbers on the order of 4 to 6 (rather than 360), but lower thrust levels have not been used since the small thrusters required are not readily available. There was also the problem that at these Bond numbers the low gravity time available from drop tower testing was insufficient to observe the liquid settle to its final quiescent state, so estimates of settling time were extrapolated.

Modeling.-The advance of digital computer technology has allowed low gravity fluids problem to be addressed via a different approach, modeling on the computer. Several techniques have been developed to model low-gravity fluid motion. The large deformation of the free surface during reorientation makes it difficult to model with a continuous free surface treatment, but several discrete methods have been evolved that are fairly successful: First, with the marker and cell algorithm which follows tracer particles; and then with the volume of fluid codes which move to a continuum within the bulk liquid while retaining the discrete nature at the free surface. Reorientation and settling have been used as a test case for these codes because the axial symmetry of the problem allow it to be addressed with a two dimensional code. Lacovic (ref. 39) was able to compare the simplified cell and marker code ERIE (Bradshaw and Kramer, (ref. 40) Bradshaw, Kramer, and Zich) (ref. 41) results to the Titan/Centaur flight data and show a favorable comparison. Hochstein, Korakianitis, Patag, and Chato (ref. 42) were able to match the work of Sumner with a modified version of NASA-VOF2D (ref. 4). They then used that model to study reorientation in two model tanks. Continuing that work, Hochstein et al (ref. 43) investigated the efficacy of pulsed thrust in emulating the lower thrust levels shown by Sumner to be desirable for efficient reorientation. Computational simulations of reorientation in a generic Space-Based Orbit Transfer Vehicle (SBOTV) propellant tank, and for a $1 / 5$ scale model of that tank, led to definition of a settling function, $\mathrm{F}_{\mathrm{s}}$, that relates the vehicle delta- $v$ incurred by the reorientation maneuver to the tank radius and the effective acceleration, $\left(\mathrm{a}_{\mathrm{e}}=\right.$ (total impulse)/time). It was shown that for a Bond number of 10 or greater, the concept of effective acceleration and the settling function were effective in correlating the computationally predicted reorientation performance for both tanks. Figure 3 shows the results and correlation.

Issues.-Propellant Reorientation has a good experimental database to compare to and several useful correlations for key velocities. However drop tower time constraints prevent the observation of the process in its entirety. Model validation has been successful when the regime bond number is above 10 , regimes below this acceleration will require further study.

\section{Tank Outflow}

Drop tower.-Tank outflow exhibits several interesting phenomena in low gravity. One is the draw down of the free surface. This results in ingestion of gas into the outlet even when a substantial amount of liquid remains in the tank. The other is the generation of a geyser from liquid momentum when outflow is stopped suddenly. Both of these cause trouble for the low gravity tank designer. As a consequence the phenomena has been investigated in a series of drop tower experiments including Derdul, Grubb and Petrash, (ref. 44) Grubb and Petrash, (ref. 45) Berenyi and Abdalla, (ref. 46) and Symons (ref. 47).

Modeling.-Modeling of this phenomenon has been somewhat limited. The one model reported (ref. 48) is of some significance though because it represents one of the 
first applications of the Volume of Fluid method to low gravity flows.

Issues.-Tank outflow contains a good body of experimental data which has been underutilized for model validation. Data may be subject to the same optical problems as the static cases.

\section{Tank Inflow}

Drop tower.-Symons (refs. 49 to 52) and Spuckler (ref. 53) studied the liquid inflow via axial jet into a broad range of tank shapes both empty and partially full. Staskus (ref. 54) extends the work of Symons by placing baffles in front of the jet. However, no attempt is made to analyze these complex flows. Instead results are reported as a ratio of improvement to the unbaffled jet Weber number. Labus (ref. 55) also studied the effect of baffles including ones that break the central jet into several small jets. Aydelott (refs. 56 to 58) looks at the problem of a recirculating jet where the liquid level is held constant. Results are classified into four flow patterns, dissipation, geyser formation, aft collection, and circulation. Aydelott's assessment that a drop in mixing accompanies the geyser formation/aft collection transition indicates the transition's importance.

Space shuttle.-The Tank Pressure Control Experiment (TPCE) has flown three times. The first flight focused on the mixing studies of Aydelott. Improvements included actual heat transfer data by using a condensing fluid (refrigerant 113) and longer duration. Bentz (refs. 59 to 61) was able to confirm the geysering and circulating regimes of Aydelott, but encountered an asymmetric regime between the two that was even more catastrophic to heat transfer than aft collection. The second flight of TPCE focused mostly on rapid boiling phenomena, but contained some further tests on mixing. Hasan (ref. 62) confirmed the findings of Bentz. The third flight (Bentz) (ref. 63) was done at a lower fill level but confirmed the results of the other flights.

Computational simulations.-Unless countermeasures are provided, solar insolation of an on-orbit cryogenic propellant tank will cause evaporation of liquid propellant and consequent over-pressurization of the tank. Aydelott's experiments (refs. 56 to 58) were part of a research program focused on one proposed countermeasure; a Thermodynamic Vent System (TVS). Sacrificial liquid is extracted from the tank, cooled by expansion through a Joule-Thomson valve, and vented overboard. Another stream of liquid is extracted from the tank, flows through a heat exchanger to be cooled by the sacrificial fluid and is then returned to the tank to suppress temperature rise, and thereby suppress evaporation. Hochstein, Gerhart, and Aydelott (ref. 64) added several physics modules and features to a derivative of the NASA SOLA-VOF Code (ref. 48) in an attempt to simulate the mixing induced by an axial-jet that reintroduces the cooled liquid to the propellant pool. Simulations of several of Aydelott's experiments correctly predicted the flow regime but were less successful in accurately predicting geyser height for cases in which a stable geyser was observed. Computational predictions for temperature fields associated with jet-induced mixing in a typical Orbit Transfer Vehicle (OTV) tank were later published by Hochstein, Ji, and Aydelott (ref. 65). A further modified version of the same code was used to predict onorbit pressurization rates in the absence of an evaporation suppression system (Hochstein, Ji, and Aydelott) (ref. 66). Another attempt at directly modeling tank pressure history during autogenous pressurization, using the FLOW3D (ref. 67) was reported by Sasmal et al. (ref. 68) These simulations exposed a significant difference between the pressurization process in the presence of slush hydrogen as compared to the process in the presence of liquid hydrogen.

Thornton and Hochstein (ref. 69) revisited the mixing tests of Aydelott with a computational model built upon the foundation of a newer code, (Kothe, Mjolsness, and Torrey) (ref. 5). These simulations were again in agreement with the observed flow pattern morphology and they were also in significantly better agreement with observed geyser heights for flows with a stable geyser. The computational simulation was used to expand the parameter space of the investigation in search of an improved correlation for the prediction of geyser height. The resulting correlation employs a jet Bond number in addition to the Bond number based on tank diameter used in Aydelott's correlation. The new correlation outperforms the old one on both the original drop-tower data and the entire collection of geyser heights associated with the expanded parameter space.

Chato (ref. 2) compared phase field model runs to the drop tower data of Aydelott. Figure 4 shows the comparison between predicted geyser height and fill level for a laminar model and the experiment. The model handed the free surface deformation, even to the point of modeling geyser growth in the regime where the free surface is no longer restrained. However, the restraining forces on Jets in the Reynolds number 630 to 900 range are seriously under predicted. This is believed to be due the lack of turbulence modeling which acts to spread the jet over a larger surface area thereby reducing the geyser height. Aydelott observed in his tests a spread angle of $2^{\circ}$ for laminar jets but $12^{\circ}$ for turbulence. This increased spread will lower the centerline velocity more quickly and increase the area of the jet at the free surface, decreasing the amount of surface deformation required to contain the jet. The under prediction at the Reynolds number 450 is harder to explain but is worse at low fill levels. It may be due to a slosh baffle at the 33 percent fill level, which prevents development of a hemispherical interface in zero gravity. The baffle acts to raise the liquid height at the centerline and flatten the free surface, which lessens the surface tension force on the jet. This effect was most pronounced for runs with 29 percent liquid volume where the measured height of the free surface above the jet is actually higher than the runs with 39 percent liquid volume. It was considered that free surface height 
above the jet was the more important parameter. Therefore model runs matched the free surface height not the liquid fill volume.

In an effort to improve the prediction at higher Reynolds number flows a simple turbulence model was introduced. Simple mixing length models of turbulence suggest that, for the free jet, flow can be approximated by using a constant turbulent viscosity. Pope (ref. 70) using the experimental data of Hussien et al. (ref. 71) shows that turbulent viscosity is constant \pm 15 percent through the bulk of the jet although it does die down to 0 at the edge. Unfortunately Pope (ref. 70) gives this constant in a nondimensional form not readily available to use in this analysis. Schlicting (ref. 72) gives another formula for the average value of turbulent viscosity as a function of mean flow rate. Using this formula $\mu_{\mathrm{t}}=0.158 \mathrm{~g} \mathrm{~cm} / \mathrm{s}$ when the velocity is $34 \mathrm{~cm} / \mathrm{s}$ and $\mu_{\mathrm{t}}=$ $0.232 \mathrm{~g} \mathrm{~cm} / \mathrm{s}$ when the velocity is $50 \mathrm{~cm} / \mathrm{s}$. It is a fairly simple matter to introduce this as a new viscosity for the bulk liquid. Figure 5 shows a comparison between steady state geyser heights from these models and the experimental geyser heights of Aydelott. The fully turbulent model overcorrects resulting in lower predicted geyser heights than experimentally measured.

In an effort to improve the modeling of geyser height a parametric variation of the value of turbulent viscosity was conducted. Overall a $0.18 \mathrm{~g} \mathrm{~cm} / \mathrm{s}$ viscosity was found to match the experimental data reasonably well. The model still under-predicted slightly most of the data but matched the 60 percent fill data very closely. Figure 6 shows a comparison between the predicted and measured geyser heights.

Issues.-Tank inflow has been extensively studied experimentally. Model validation against this data has been only adequate. The core issue appears to be a lack of a detailed measurement of the flow field since the free surface shape seems quite sensitive to the level of turbulence in the inflow jet. Optical distortion is also an issue, particularly when the surface deformation is small.

\section{Pressure Rise and Stratification in Low Gravity}

Panzarella, and Kassemi (refs. 73 to 75 ) consider the difficult problem of low gravity stratification On the ground, the liquid normally settles to the bottom of the tank, but in microgravity, it may be anywhere. Since the contact angle of liquid Hydrogen is nearly zero, it is likely that it will completely wet the tank wall. Thus, the initial configuration considered by Panzarella, and Kassemi corresponded to the situation where the vapor has accumulated into a single spherical vapor region completely surrounded by liquid. The vapor region is free to evolve over time, and it was shown that under normal microgravity conditions it will reach the tank wall before there is any appreciable pressure rise.

The liquid equations were solved by using an in-house modified version of the Galerkin finite element code FIDAP (ref. 7) that is extended by providing coupling with the lumped-vapor model. The temperature and velocity fields were discretized using 9-node quadratic elements, and the pressure was discretized using a linear discontinuous approximation (the three pressure unknowns per element are the coefficients of the linear polynomial approximating the pressure). The position of each node on the free surface was adjusted by using a front-tracking approach. The interior nodes were moved using the method of straight spines. They were shifted proportionally along straight, nearly radial lines passing through the free surface. Validation of code predictions is extremely difficult due to the long timescales involved in the process and the hazardous nature of the fluid of interest. Several approaches could be taken as follows: Calibrate the code on ground test and hope the physics remains constant over the several order of magnitude shift in driving force; Calculate the thermodynamic equilibrium process and use as a bound for the solution; Examine the results and asses them for reasonableness to what is expected. Three cases were considered to study the problem over all the relevant timescales.

In the first case, the spherical vapor bubble is assumed to be initially at the center of the tank, and the history of the tank pressure as well as the evolution of the liquid flow and thermal fields are examined by following the deforming bubble as it approaches the tank wall. Its motion is driven solely by the buoyancy force resulting from the density jump across the liquid-vapor interface. Fluid motion is shown in figure 7. Although the motion is reasonably rapid, its duration of 600 seconds far exceeds any drop tower test.

Since the timescale for the vapor bubble to reach the tank wall is much shorter than the conduction or convection timescales, the second case study focuses on the temperature, pressure and flow fields that develop over a longer time span while the vapor bubble remains in a fixed position near the tank wall. Fluid was still allowed to slip over the interface by assuming the vapor shear stress is negligible. This permitted the study of the average long-term pressurization of the tank. Figure 8 shows the pressure rise compared to equilibrium pressure rise and heat transfer for this condition.

Finally, the third case examined the possibility of controlling the tank pressure in microgravity with the mixing provided by a subcooled liquid jet. Again, the bubble is positioned near the wall, and the tank is pressurized for an additional 75 days. Three different jet speeds were considered, spanning three orders of magnitude. For each one, the time required to bring the pressure back down to its initial value was determined. Figure 9 shows the pressure rise compared to equilibrium pressure rise and heat transfer for this condition.

Issues.-Pressure rise and stratification in low gravity is an important issue for model simulation. Thermodynamic analysis provides a useful check as to the reasonableness of the simulation, but cannot provide enough information to validate process transients. The time constants of process 
(on the order of minutes to days) are beyond drop tower test capabilities.

\section{Other Topics}

The preceding history of experimental, analytical, and computational research on thermal-fluid processes occurring in a reduced gravity environment is useful, but not exhaustive. It is concentrated in the field of low gravity propellant management. The examples presented help to show the issues and concerns with the establishment of benchmark cases from the existing literature.

Other areas of research in low gravity thermal-fluid processes may hold analytical and experimental findings of value for code validation. For example, an entire body of literature is devoted to "materials processing" in a lowgravity environment, (i.e., Sen and Davis, (ref. 75) Sasmal and Hochstein (ref. 76)). Another research topic not explored in this survey is the use of body forces (such as those induced by a magnetic field); to suppress motion; to improve the performance of crystal growth processes; to produce a desirable motion such as reorientation; or to positively position liquids within containers in a low-gravity environment (Martin and Holt, (ref. 77) Marchetta and Hochstein, (ref. 78) Marchetta et al. (ref. 79)). The establishment of a set of V\&V benchmark cases against which the fidelity of models claiming to simulate thermalfluid processes occurring in a reduced gravity environment can be judged will require contributions from the entire research community.

\section{Summary}

A variety of zero-g fluid motion problems have been described for which experimental or analytical data are available for use in validation of numerical codes. Overall, although there has been much sub-scale testing of zero-g fluid motion, there are several things lacking in the published literature. Most of the data is described by empirical correlation rather than fundamental relation. Detailed measurements of the flow field have not been made. Free surface shapes are observed but through thick plastic cylinders, and therefore subject to a great deal of optical distortion. Heat transfer research also been highly constrained since the time for the processes of interest to evolve is greater than that available in drop tower experiments.

Other areas of research in low gravity thermal-fluid behavior may hold analytical and experimental findings of value for code validation. The examples presented help to show the issues and concerns with the establishment of benchmark cases from the existing literature.

The achievement of true benchmarks in other fields of CFD has required dedicated experiments, specifically designed with the concept of code validation in mind, and there is every reason to expect this will also be the case for low gravity fluid behavior. Modern flow visualization techniques are available to make vast improvements in measurement of low gravity fluid behavior. Miniaturization of lasers and electronics has reduced the size of the instruments required for flow visualization so that testing within the constraints of drop towers and other low gravity facilities is practical. Modern CFD modeling has great potential for use in scaling small scale tests to objects of practical size, but without accurate knowledge of the fluid flows, heat transfer and surface deformation validation of the codes is impossible. The authors' welcome further discussion on the establishment of a set of V\&V benchmark cases against which the fidelity of models claiming to simulate thermal-fluid processes occurring in a reduced gravity environment can be judged.

\section{References}

1. Chato, David J. "Influence of Turbulence on the Restraint of Liquid Jets by Surface Tension in Microgravity," AIAA2002-0758, January 2002.

2. Chato, David J. "Penetration of the Free Surface by Liquid Jets in Microgravity," PhD. Dissertation, Case Western Reserve University, January 2004.

3. Jacqmin, D. "Calculation of Two-Phase Navier-Stokes Flows Using Phase-Field Modeling," Journal of Computational Physics 155, 96-127, 1999.

4. Torrey, Martin D. et al. "NASA-VOF2D: A Computer Program for Incompressible Flows with Free Surfaces," LA-10612-MS, Los Alamos National Laboratory, December 1985.

5. Kothe, D.B., Mjolsness, R.C., Torrey, M.D., "RIPPLE: A Computer Program for Incompressible Flow with Free Surfaces," Los Alamos National Laboratory, LA-12007-MS, 1991.

6. Brackbill, J.U., Kothe, D.B., Zemach, C., "A Continuum Method for Modeling Surface Tension," Journal of Computational Physics vol. 100, no. 2, June 1992.

7. Engelman, S., and R.L. Sani, Finite element simulation of incompressible flows with free/moving surface, in: Numerical Methods in Laminar and Turbulent Flows, Pineridge Press, Swansea, U.K., 1984.

8. Oberkampf, W.L.; Trucano, T.G., "Verification and Validation in Computational Fluid Dynamics," Sandia National Laboratories, SAND2002-0529, 2002.

9. DoD, "DoD Directive no. 5000.59: Modeling and Simulation (M\&S) Management," Defense Modeling and Simulation Office, Office of the Director of Defense Research and Engineering, www.dmso.mil/docslib.

10. DoD, "Verification, Validation, and Accreditation (VV\&A) Recommended Practices Guide," Defense Modeling and Simulation Office, Office of the Director of Defense Research and Engineering, www.dmso.mil/docslib.

11. Roache, P.J., "Verification and Validation in Computational Science and Engineering," Hermosa Publishers, Albuquerque, NM, 1998. 
12. AIAA, "Guide For the Verification and Validation of Computational Fluid Dynamics Simulations," American Institute of Aeronautics and Astronautics, AIAA-G-077-1998, Reston, VA, 1998.

13. Concus, Paul "Static menisci in a Vertical Right Circular Cylinder," J. Fluid Mech. vol. 34, Part 3, pp. 481-495, 1968.

14. Reynolds, W.C., Saad, M.A. and Satterlee, H.M. "Capillary Hydrostatics and Hydrodynamics at Low G," Stanford University Technical Report LG-3, 1964.

15. Hastings, L.J. and Rutherford, R. "Low Gravity Liquid-Vapor Interface Shapes in Axisymmetric Containers and a Computer Solution," NASA TM X-53790, 1968.

16. Petrash, D.A. et al. "Effect of Surface Energy on the LiquidVapor Interface Configuration During Weightlessness," NASA TN D-1582.

17. Labus, T.L. "Liquid-vapor Interface Configuration in Annular Cylinders," NASA TM X-1973, 1970.

18. Salzmann, J.A. "Low-Gravity Liquid-Vapor Interface Configurations in Spherical Containers," NASA TN-D-5648, 1970.

19. Spuckler, C.M. and Abdalla, K.L. "Zero-Gravity LiquidVapor Interface Configuration in Conical Tanks," NASA TM X-2400, 1971.

20. Petrash, D.A., Nussle, R.C., and Otto, E.W. "Effect of Acceleration Disturbances Encountered in the MA-7 Spacecraft on the Liquid-Vapor Interface in a Baffled Tank During Weightlessness," NASA TN-D-1577, 1963.

21. Abdalla, K.L., Flage, R.A. and Jackson, R.G. "Zero-Gravity Performance of Ullage Control Surface with Liquid hydrogen while subjected to unsymmetrical radiant Heating," NASA TM X-1001, 1964.

22. Siegert, C.E., Petrash, D.A., and Otto, E.W. "Time Response of Liquid-Vapor Interface After Entering Weightlessness," NASA TN-D-2458, 1964.

23. Fung, F.C.W.; "Dynamic Response of Liquid in Partially Filled Containers Suddenly Experiencing Weightlessness," Fluid Mechanics and Heat Transfer Under Low Gravity, Lockheed Missiles and Space Co. 1965.

24. Hollister, M.P.; and Satterlee, H.M.; "Low Gravity Liquid Reorientation," Fluid Mechanics and Heat Transfer Under Low Gravity, Lockheed Missiles and Space Co. 1965.

25. Brakke, K.A. "The Surface Evolver," Experimental Mathematics, vol. 1, pp. 141-165, 1992.

26. Tegart, James, "Three-Dimensional Fluid Interfaces in Cylindrical Containers," AIAA-91-2174, June 1991.

27. Dominick, S. and Tegart, J., "Orbital Test Results of a Vaned Liquid Acquisition Device," AIAA-94-3027, June 1994.

28. Collicott, S.H. and Weislogel, M.M. "Corner Radius Effects on Capillary Instability in Tank Geometries," AIAA-20013824, 2001.

29. Concus, P. and Finn, R. "Dichotomous behavior of Capillary Surfaces in Zero Gravity," Microgravity Sci. Tech III (2) pp. 87-92, 1990.

30. Weislogel, M.M. and Collicott, S.H. "Analysis of Tank PMD Rewetting Following Thrust Resettling," AIAA-2002-0757, Jan. 2002.

31. Collicott, S.H. and Weislogel, M.M. "Modeling of the Operation of the VTRE Propellant Management Device," AIAA-2002-4140, July, 2002.

32. Chato, D.J. and Martin, T.A. "Vented Tank Resupply Experiment-Flight Test Results," AIAA-97-2815, July 1997.
33. Collicott, S.H. and Weislogel, M.M. "Review of Surface Evolver Validation Tests for Zero-Gravity Fluids Applications," AIAA-2003-0999.

34. Lacovic, Raymond F. Frederick C. Yeh, Steven V. Szabo Jr., R.J. Brun, Andrew J. Stofan, and James A. Berns. "Management of Cryogenic Propellants in a Full Scale Orbiting Space Vehicle," NASA TN-D-4571, May 1968.

35. Masica, William J. and Donald A. Petrash. "Motion of Liquid-Vapor Interface in Response to Imposed Acceleration," NASA TN-D-3005, September 1965.

36. Salzman, Jack A. and William J. Masica. "Experimental Investigation of Liquid-Propellant Reorientation," NASA TND-3789, January 1967.

37. Salzman, Jack A. William J. Masica, and Raymond F. Lacovic. "Low-Gravity Reorientation in a Scale-Model Centaur Liquid Hydrogen Tank," NASA TN-D-7168, February 1973.

38. Sumner, Irving E. "Liquid Propellant Reorientation in a Low-Gravity Environment," NASA TM-78969, July 1978.

39. Lacovic. Raymond F. "Centaur Zero Gravity Coast and Engine Restart Demonstration on the Titan/Centaur (TC-2) Extended Mission," NASA TM X-71821, October 1975.

40. Bradshaw R.D. and J.L. Kramer. "An Analytical Study of Reduced Gravity Propellant Settling," NASA CR-134593, Feb. 1974.

41. Bradshaw R.D., J.L. Kramer, and J.L. Zich. “An Analytical Study of Reduced-Gravity Flow Dynamics," NASA CR-135023, April 1976.

42. Hochstein, J.I., Korakianitis, T.P., Patag, A.E., Chato, D.J., "Modeling of Impulsive Propellant Reorientation," AIAA J. Propulsion and Power, vol. 7, no. 6, November-December 1991.

43. Hochstein, John I., Alfredo E. Patag, T.P. Korakianitis, and David J. Chato. "Pulsed Thrust Propellant Reorientation: Concept and Modeling," AIAA Journal of Propulsion and Power vol. 8, no. 4, July 1992.

44. Derul, J.D. Grubb, L.S. and Petrash, D.A. "Experimental Investigation of Liquid Outflow from Cylindrical Tanks During Weightlessness," NASA TN D-3746, December 1966.

45. Grubb, L.S. and Petrash, D.A. "Experimental Investigation of Interfacial Behavior Following Termination of Outflow in Weightlessness," NASA TN-D-3897, April 1967.

46. Berenyi, S.G. and Abdalla, K.L. "Vapor Ingestion Phenomenon in Hemispherically Bottomed Tanks in Normal Gravity and in Weightlessness," NASA TN-D-5704, April 1970.

47. Symons, E.P. "Effect of Throttling on Interface Behavior and Liquid Residuals in Weightlessness," NASA TM X-3034, May 1974.

48. Hotchkiss, R.S., "Simulation of Tank Draining Phenomena with the NASA SOLA-VOF Code," LASL Report LA-8163MS, 1979.

49. Symons, E.P.; Nussle, R.C. and Abdalla, K.L. "Liquid Inflow to Initially Empty, Hemispherical Ended Cylinders During Weightlessness": NASA TN D 4628: June 1968.

50. Symons, Eugene P., Nussle, Ralph C., "Observations of Interface Behavior During Inflow to an Elliptical Ended Cylinder in Weightlessness," NASA TM X-1719, January 1969.

51. Symons, Eugene P. "Interface Stability During Liquid Inflow to Initially Empty Hemispherical Ended Cylinders in Weightlessness," NASA TM X-2003, April 1970. 
52. Symons, Eugene P., Staskus, John V., "Interface Stability During Liquid Inflow to Partially Full, Hemispherical Ended Cylinders in Weightlessness," NASA TM X-2348, August 1971.

53. Spuckler, Charles M. "Liquid Inflow to Initially Empty Cylindrical Tanks in Low Gravity," NASA TMX-2613, August 1972.

54. Staskus, John V, "Liquid Inflow into a Baffled Cylindrical Tank During Weightlessness," NASA TM X-2598, August 1972.

55. Labus, T.L., Aydelott, J.C., Andracchio, C.R., "Effect of Baffles on Inflow Patterns in Spherical Containers During Weightlessness," NASA TMX-2670, November 1972.

56. Aydelott, J.C. "Axial Jet Mixing of Ethanol in Spherical Containers During Weightlessness," NASA TM X-3380: April 1976.

57. Aydelott, J.C. "Axial Jet Mixing of Ethanol in Cylindrical Containers During Weightlessness," NASA TP-1487: July 1979.

58. Aydelott, J.C.: "Modeling of Space Vehicle Propellant Mixing," NASA TP-2107: January 1983.

59. Bentz, M.D., et al. "Tank Pressure Control Experiment-A Low-g Mixing Investigation," AIAA-90-2376.

60. Bentz, Michael D., "Tank pressure control in low gravity by jet mixing," NASA-CR-191012, March 1993.

61. Bentz, M.D., Knoll, R.H., Hasan, M.M., Lin, C.S., "Low-g fluid mixing-Further results from the Tank Pressure Control Experiment," AIAA PAPER 93-2423, Jun. 1993.

62. Hasan, Mohammad M., Lin, Chin S., Knoll, Richard H., and Bentz, Michael D., "Tank Pressure Control Experiment: Thermal Phenomena," NASA TP 3564, March 1996.

63. Bentz, Michael D, et al. "Tank Pressure Control ExperimentResults of three space flights," AIAA Paper 97-2816, July 1997.

64. Hochstein, J.I., Gerhart, P.M., Aydelott, J.C., Computational Modeling of Jet Induced Mixing of Cryogenic Propellants in Low-G, AIAA-84-1344.

65. Hochstein, J.I., Ji, H.-C., Aydelott, J.C., "Temperature Fields Due to Jet Induced Mixing in a Typical OTV Tank," AIAA87-2017, AIAA 23rd Joint Prop. Conf., June 1987.

66. Hochstein, J.I., Ji, H.-C., Aydelott, J.C., "Prediction of SelfPressurization Rate of Cryogenic Propellant Tankage," AIAA J. Propulsion and Power, vol. 6, no. 1, pp. 11-17, Jan.-Feb., 1990.
67. "FLOW3D; Computational Modeling Power for Scientists and Engineers," Flow Science, Inc., Los Alamos, New Mexico, 1988.

68. Sasmal, G.P., Hochstein, J.I., M.C., Hardy, T.L., "Influence of Heat Transfer Rates on Pressurization of Liquid/Slush Hydrogen Propellant Tanks," AIAA-93-0278, AIAA 31st Aerospace Sciences Mtg. Jan 1993.

69. Thornton, R.J., Hochstein, J.I., "Microgravity Geyser and Low Field Prediction," AIAA-00-0858, AIAA 38th Aerospace Sciences Mtg., Jan. 2000.

70. Pope, S.B. Turbulent Flows. Cambridge University Press, 2000.

71. Hussien, H.J. Capp, S.P. George, W.K. "Velocity Measurements in a High-Reynolds-Number, MomentumConserving, Axisymmetric, Turbulent Jet," Journal of Fluid Mechanics vol. 258 pp. 31-75, 1994.

72. Schlichting, H.; and Gersten, K. Boundary-Layer Theory. 8th Edition Springer-Verlag 2000. Panzarella, C.H. M. Kassemi, "On the validity of purely thermodynamic descriptions of two-phase cryogenic fluid storage," Journal of Fluid Mechanics 484 (2003) 136-148.

73. Panzarella, C.H. M. Kassemi, "Pressurization of spherical cryogenic tanks in space," Journal of Spacecraft and Rockets, submitted (2003).

74. Panzarella, C.H., D. Plachta, and M. Kassemi, "Pressure control of large cryogenic tanks in microgravity," 20th Space Cryogenics Workshop, Girdwood, Alaska. Also Cryogenics, submitted for publication (2003).

75. Sen, A.K., Davis, S.H., "Steady Thermocapillary Flows in Two-Dimensional Slots," J. Fluid Mechanics, vol. 121, pp. 163-186, 1982.

76. Sasmal, G.P., Hochstein, J.I., "Marangoni Convection with a Curved and Deforming Free Surface in a Cavity," ASME J. of Fluids Engineering vol. 116, pp. 577-582, Sep. 1994.

77. Martin, J.J., Holt, J.B., "Magnetically Actuated Propellant Orientation Experiment, Controlling Fluid Motion with Magnetic Fields in a Low-Gravity Environment," NASA TM 210129, 2000.

78. Marchetta, J.G., Hochstein, J.I., “A Computational Model of Magnetic Positive Positioning in Reduced Gravity," ST-99W.210, IAF 50th Int'l. Astronautical Congress, Oct. 1999.

79. Marchetta, J.G., Hochstein, J.I., Sauter, D.R., Simmons, B.D., "Modeling and Prediction of Magnetic Storage and Reorientation of LOX in Reduced Gravity," AIAA-20021005, AIAA 40th Aerospace Sciences Mtg., Jan 2002. 

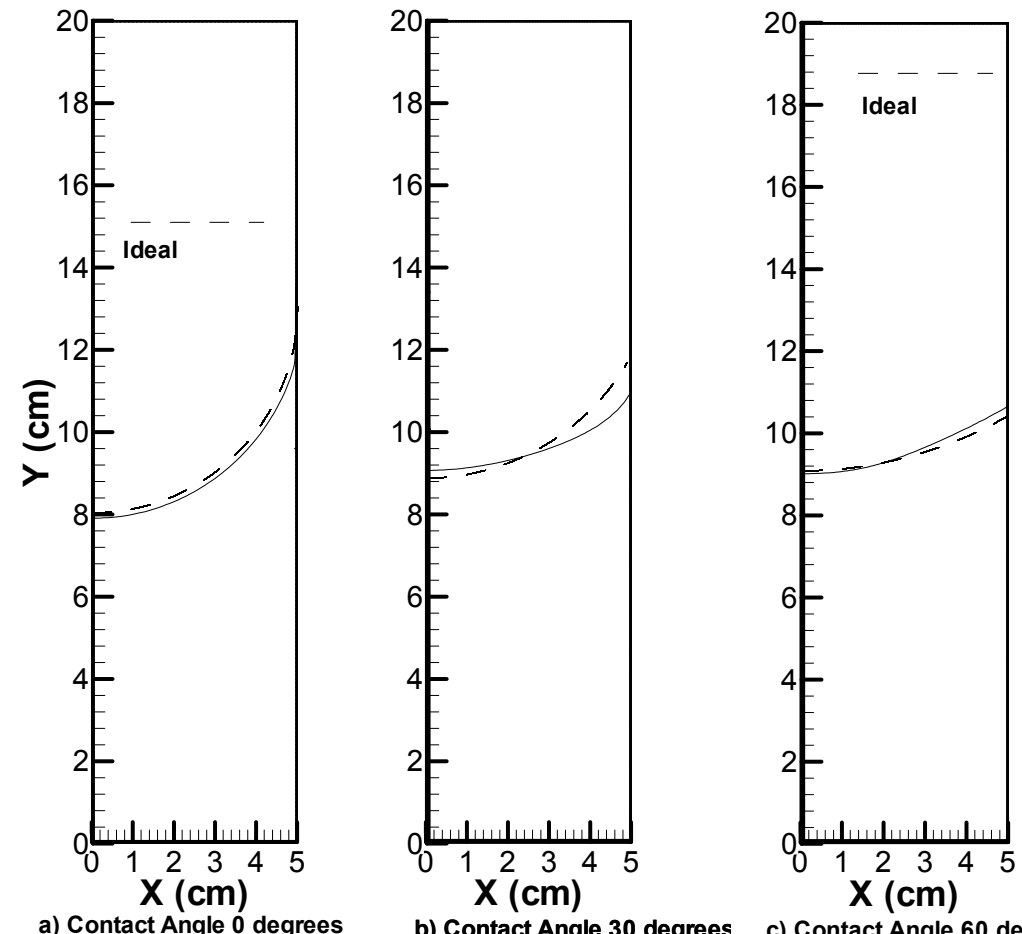

Figure 1.-Near Equilibrium Free Surface Shapes.

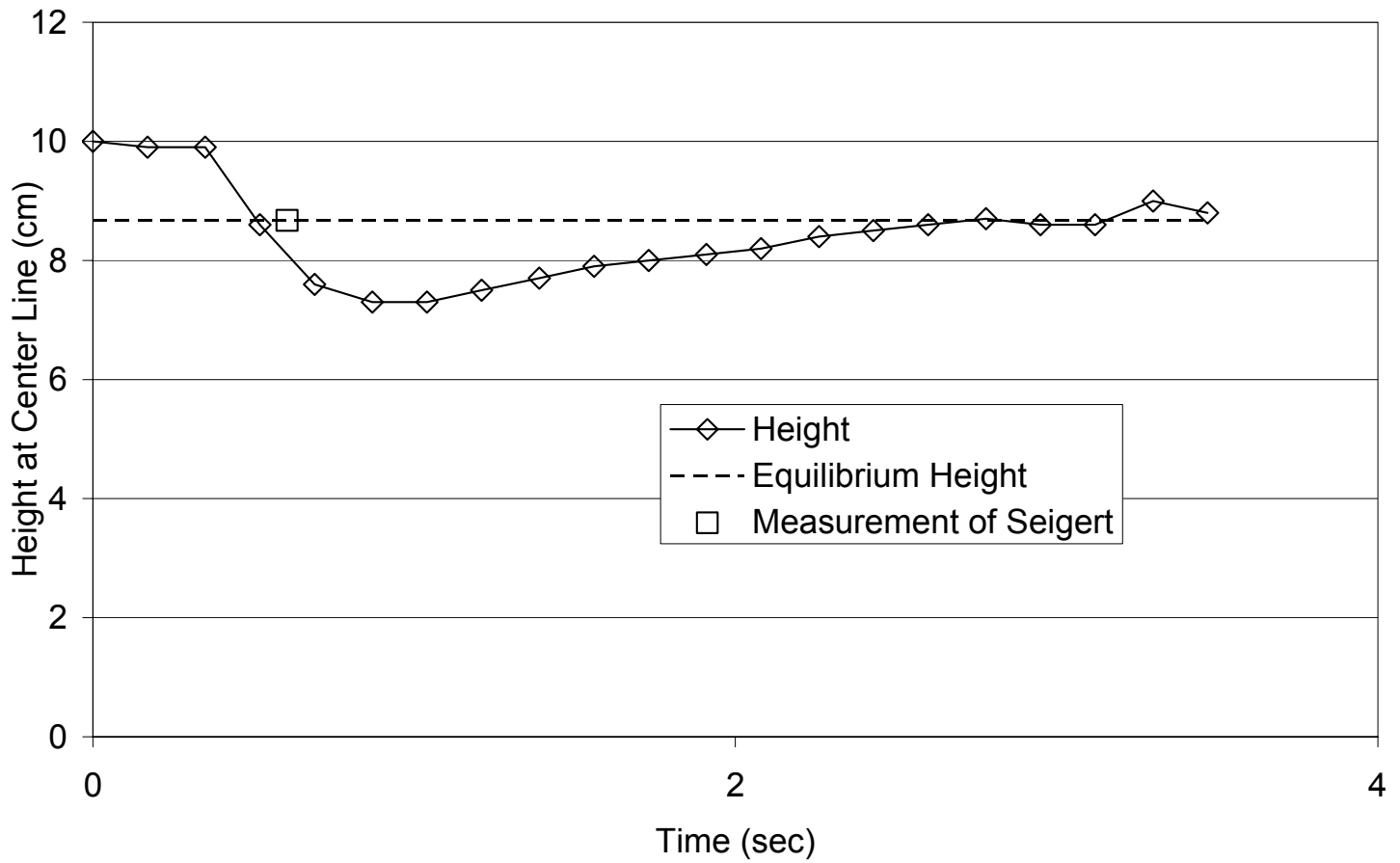

Figure 2.-Motion of Liquid in Response to the removal of Gravity $8 \mathrm{~cm}$ Diameter Tank filled to a Starting Flat Height of $10 \mathrm{~cm}$. 


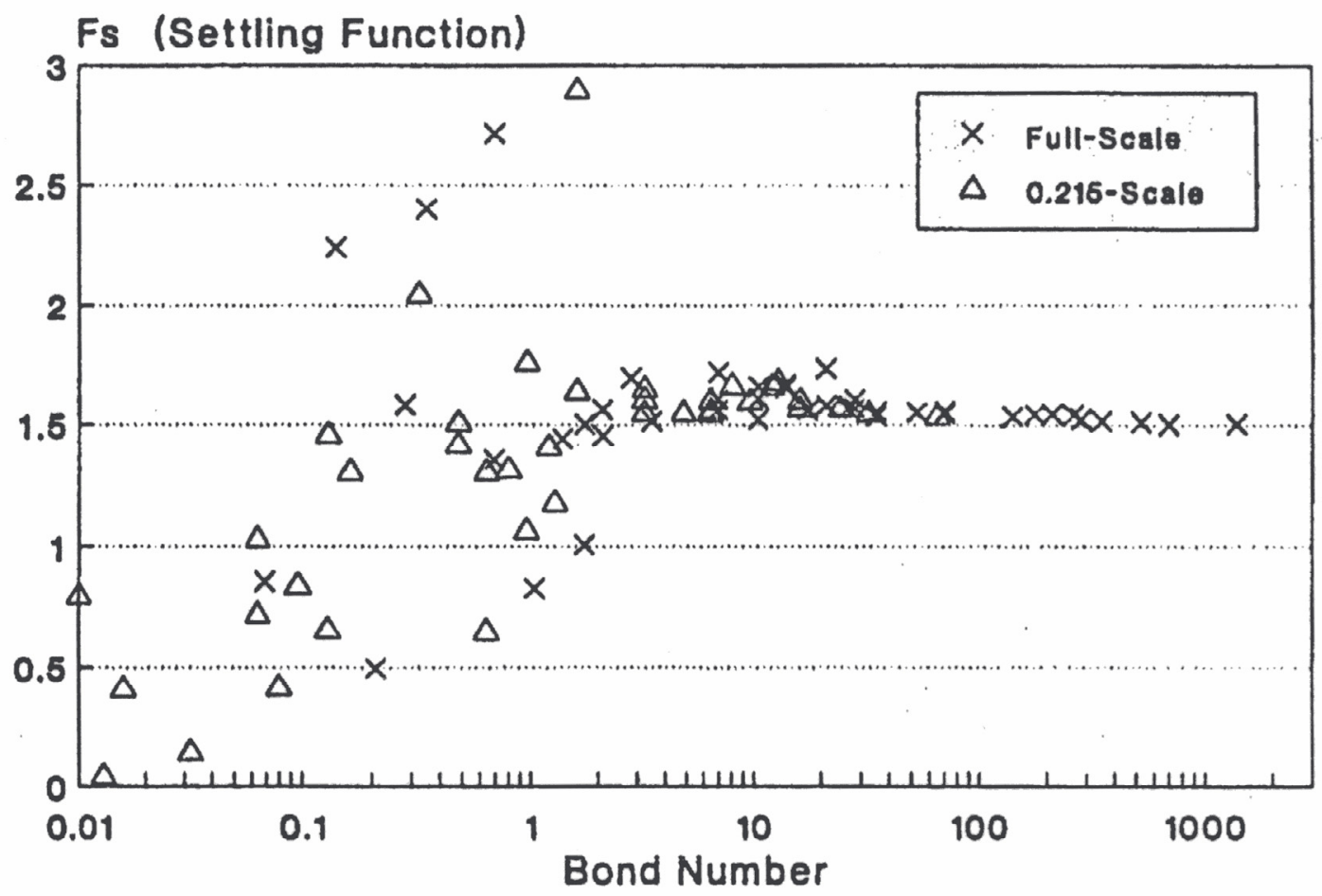

Figure 3.-Fs versus Bo for 50 percent filled Space Based OTV.

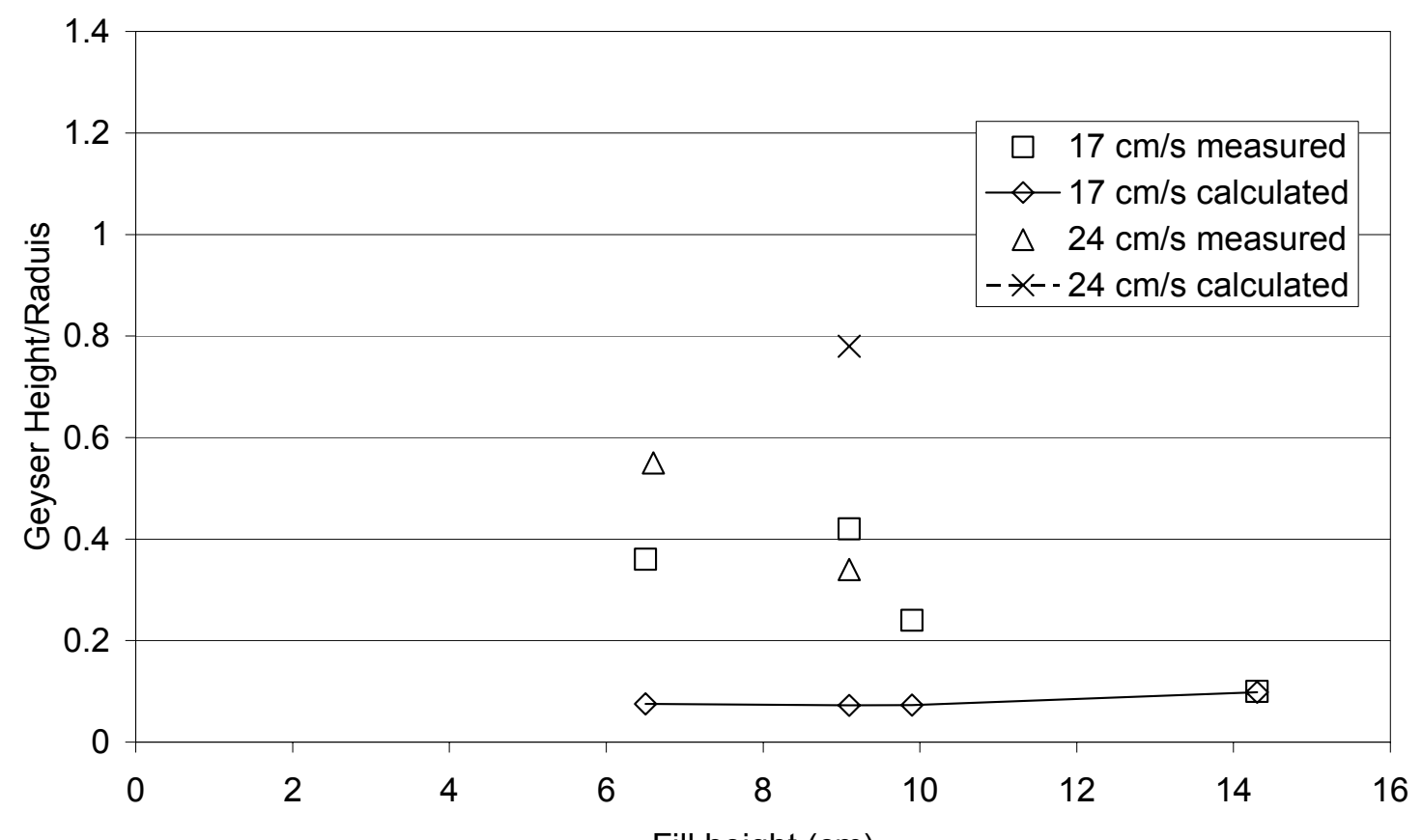

Fill height $(\mathrm{cm})$

Figure 4.-Non-Dimensional Geyser Height Comparison Calculated versus Measured for Laminar Flow. 


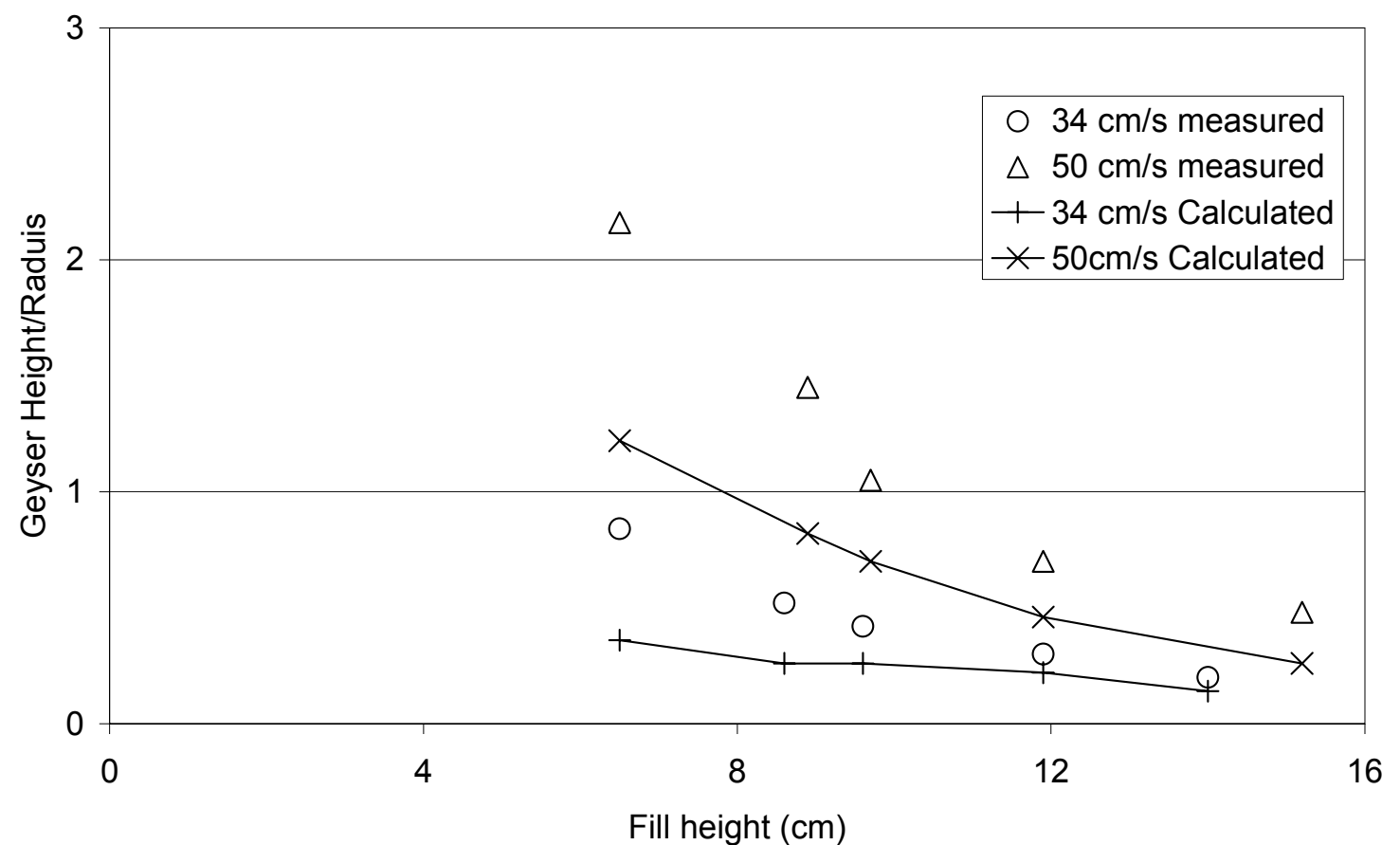

Figure 5.--Non-Dimensional Geyser Height Comparison Calculated versus Measured for Full Turbulence.

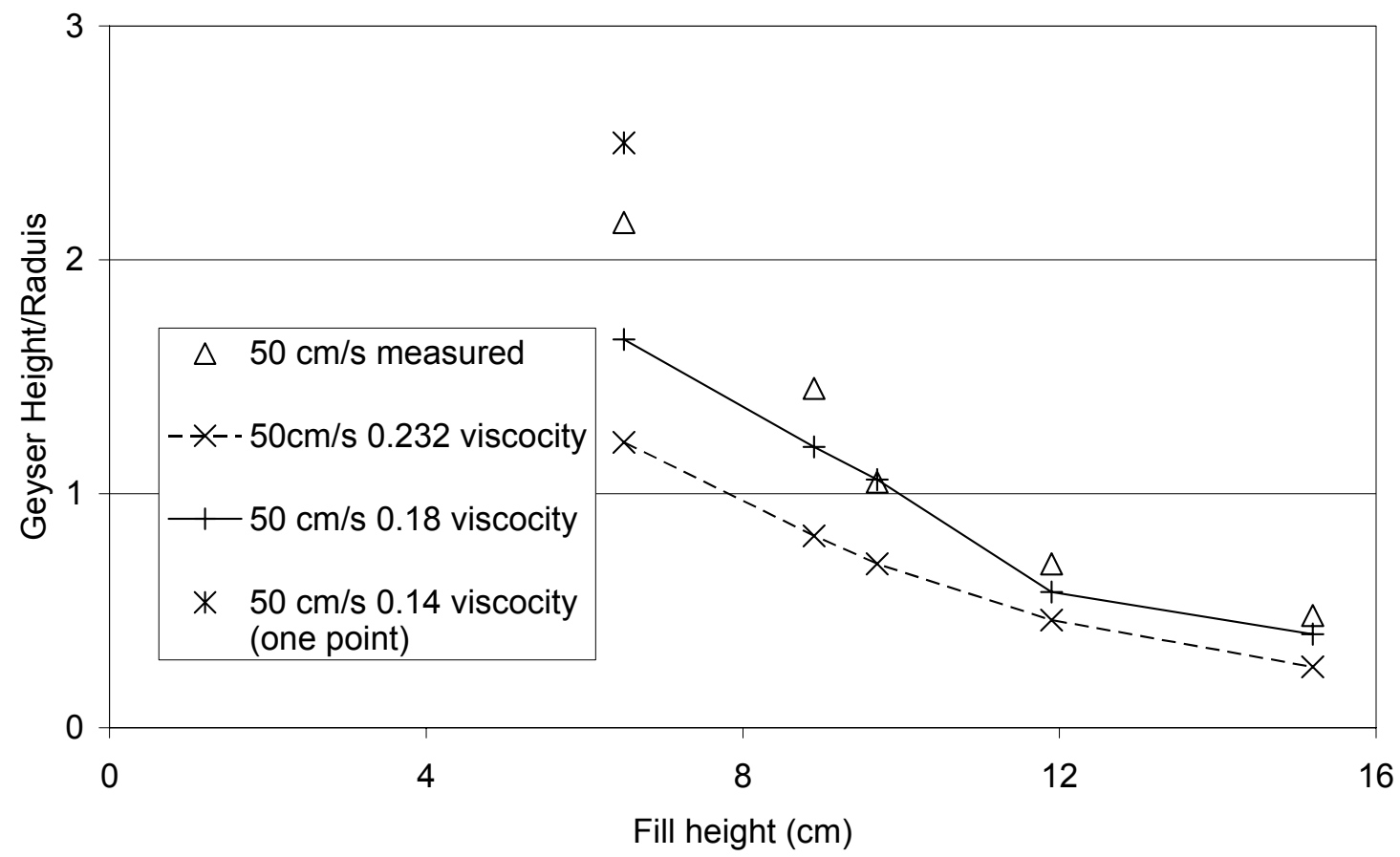

Figure 6.-Non-Dimensional Geyser Height Comparison Calculated versus Measured for Parametric Turbulence. 

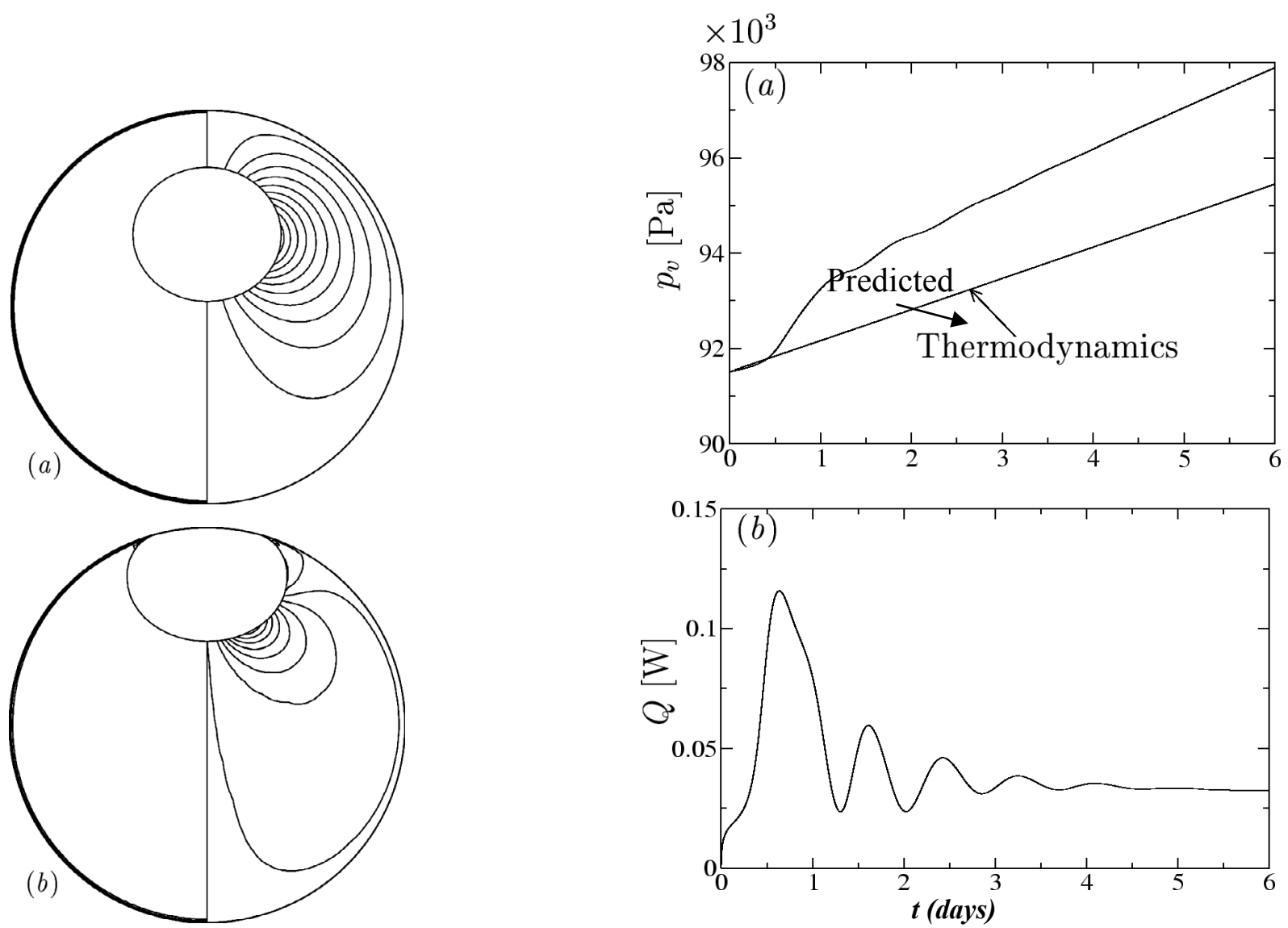

Figure 8. - The initial (a) pressure rise and (b) net heat flow into the vapor with the vapor region at the wall.

Figure 7.- Isotherms and streamlines for (a) $\mathrm{t}=259 \mathrm{~s}$, (b) $\mathrm{t}=463 \mathrm{~s}$, and (c) $\mathrm{t}=567 \mathrm{~s}$, as the initially-centered spherical vapor bubble rises only due to buoyancy force. 

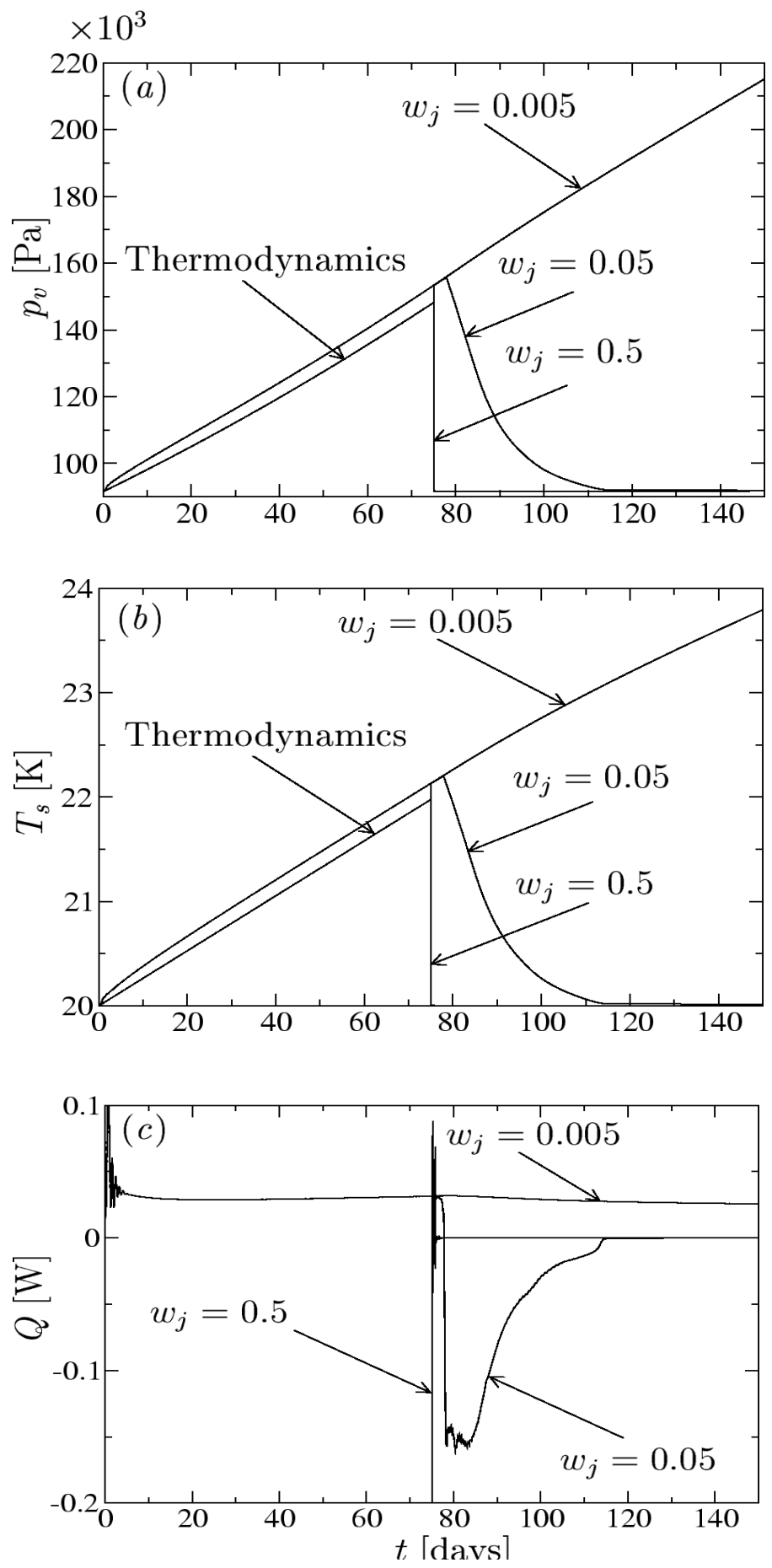

Figure 9.-The long-term (a) pressure, (b) saturation temperature and (c) total heat before and after the subcooled jet is turned on at $\mathrm{t}=75$ days. 


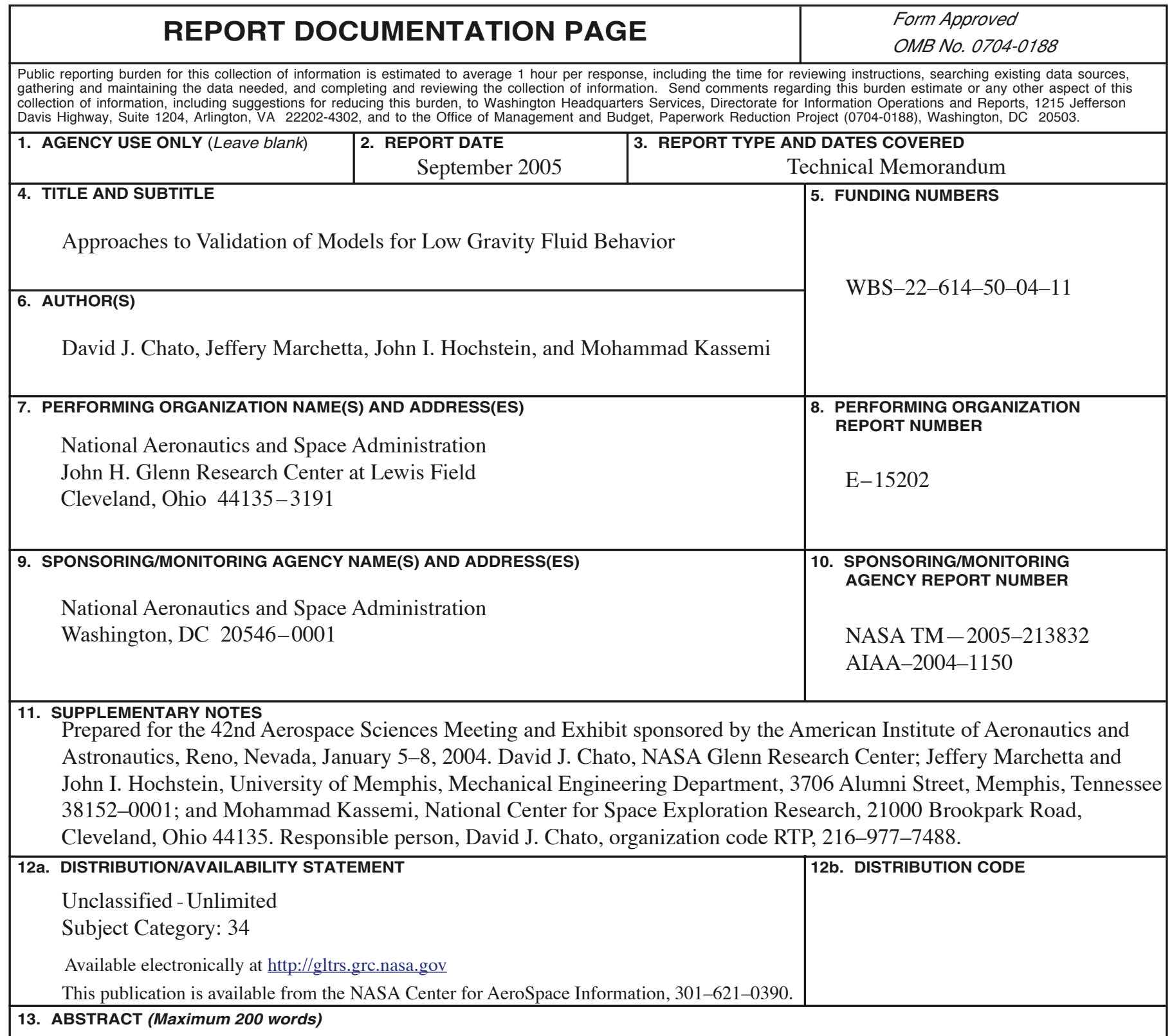

This paper details the author experiences with the validation of computer models to predict low gravity fluid behavior. It reviews the literature of low gravity fluid behavior as a starting point for developing a baseline set of test cases. It examines authors' attempts to validate their models against these cases and the issues they encountered. The main issues seem to be that: Most of the data is described by empirical correlation rather than fundamental relation; Detailed measurements of the flow field have not been made; Free surface shapes are observed but through thick plastic cylinders, and therefore subject to a great deal of optical distortion; and Heat transfer process time constants are on the order of minutes to days but the zero-gravity time available has been only seconds.

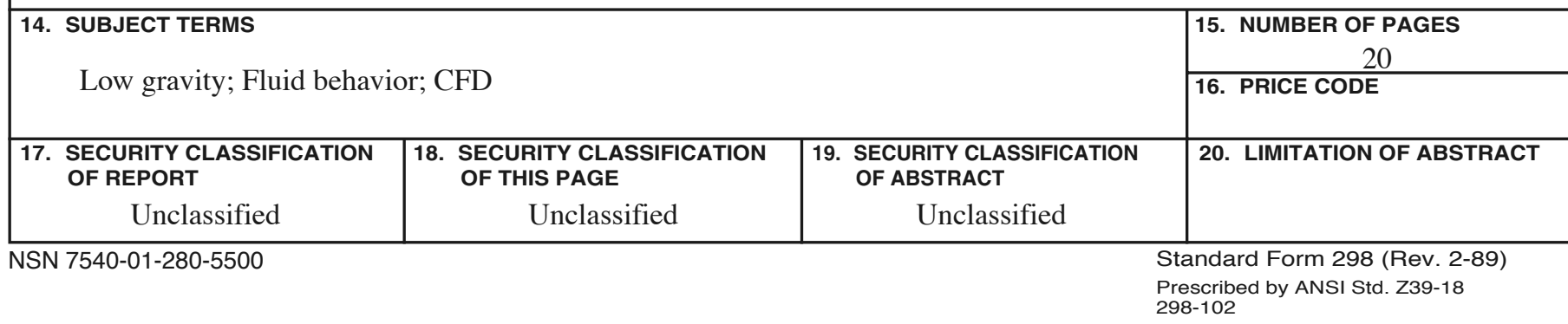



